\title{
Contribución al estudio de la dentición del perro sin pelo del Perú
}

\section{Contribution to the study of the teething of the dog without hair of Peru}

\author{
Luis Alexis Urbano Torrico*
}

http://dx.doi.org/10.21503/CienciayDesarrollo.2007.v8.02

\section{RESUMEN}

El perro sin pelo del Perú ha sido declarado patrimonio cultural de la nación mediante Ley No 27537 del 3 de octubre del 2001, y asimismo, por Resolución Directoral de la Nación No 001-2001/INC (0401-2000), el Instituto Nacional de Cultura ha dispuesto su protección en todos los sitios arqueológicos de la costa.

El presente trabajo de investigación se realizó en la ciudad de Lima, durante el período que va de octubre del 2003 a febrero del 2004. Para el efecto se procedió a observar la cavidad bucal de este animal para determinar la ausencia de dientes y a registrar los datos en un odontograma. Como muestra fueron tomados todos los perros sin pelo del Perú mayores de un año inscritos en la ciudad de Lima, que se contaron en número de 50. Los perros fueron clasificados por sexo (19 machos y 31 hembras) y por talla: pequeños (4 ejemplares), medianos (6 ejemplares) y grandes (30 ejemplares), y se les asignó un código numérico. El análisis de los datos de los datos se realizó utilizando la estadística descriptiva, analizando el número y porcentaje de dientes ausentes. Del total de perros de la muestra, se encontró que todos presentaban ausencia de dientes, hallándose como máximo 30 dientes ausentes, y como mínimo, 4 dientes ausentes. El diente más comprometido en el maxilar fue el tercer premolar derecho, ausente en 38 ejemplares. En la mandíbula, el tercer premolar izquierdo fue el más ausente, determinándose su ausencia en 42 perros. En promedio, los machos carecían de 20 dientes, y las hembras, de 17. La ausencia de dientes no depende de la talla, ni tampoco de la edad.

De los 50 ejemplares tomados como muestra, se observó que 15 de ellos presentaban una persistencia de los caninos de leche. El único caso de simetría bilateral es el del primer premolar de la mandíbula, el cual siempre estuvo presente, en tanto que los demás dientes siempre estuvieron ausentes en uno u otro caso.

Palabras clave: perro sin pelo del Perú, diente, ausencia.

\section{ABSTRACT}

The Peruvian Hairless Dog has been declared Cultural Patrimony of the Nation by means of law No 27537 since October of 2001 and also by means of National Directorial Resolutions of the Nation No 001-2000/INC-DN (04-01-2000) the National Institute of culture has ordered the protection of this breed in all the archaeological sites of the Coast.

This investigation study has been carried out in the city of Lima, during the period October 2003 - February. First, the oral cavity was observed specifically to determine the absence of teeth and to register it in an odontogram. All the adult Peruvian hairless dogs (over 1 year old) registered in the Peruvian Kennel Club of Lima used as sample; 50 of them were found. The dogs have been sorted by sex ( 19 males and 31 females) and by size: small (4 samples), medium ( 6 samples) and large ( 40 samples). Each one was assigned with a numeric code. The analysis of the data has been performed with a descriptive statistic approach, and the number and percentage of absents teeth were analyzed. Of the total of dogs used as

* Licenciado por la Facultad de Medicina Veterinaria de la Universidad Alas Peruanas. 
sample, it was found that all dogs have absent teeth, having 30 absent teeth as maximum, 4 absent teeth as minimum, and an average of 18 absent teeth. The most absent tooth in the superior maxillary was the $3^{\text {rd }}$ right premolar, absent in 38 samples $(76 \%)$ In the inferior maxillary the $3^{\text {rd }}$ left premolar was the most absent tooth, the absence was found in $42 \mathrm{dogs}(84 \%)$. In average, the males had 20 absent teeth and the females 17 . The absence of teeth does not depend on the size or the age. Of the dogs used as sample, it was observed that 15 of them had a persistence of temporal canines. The only case of bilateral symmetry is the $1^{\text {st }}$ molar of the inferior maxillary, which has always been present in all the cases; the other teeth were always absent in one case or another.

Key words: Peruvian hairless dog, tooth, absence.

\section{INTRODUCCIÓN}

Las investigaciones y aportes sobre el perro sin pelo del Perú son muy escasas, por lo cual se hace vital el estudio de sus características, para un mayor conocimiento de esta raza.

El perro sin pelo del Perú, como ya hemos anotado, ha sido declarado patrimonio cultural de la nación (1), y el INC ha dispuesto su protección en todos los sitios arqueológicos de la costa peruana (2). Así como es obligación del Estado promover la conservación de la diversidad biológica, también es una obligación permanente del Estado y de las personas naturales y jurídicas velar por la conservación, defensa, recuperación, aprovechamiento sostenido y difusión del patrimonio nacional (3).

La Constitución Política del Perú señala en su artículo 68 la obligación del Estado de promover la conservación de la diversidad biológica. Y en concordancia con esto, el Código del Medio Ambiente establece que los recursos naturales constituyen un patrimonio común de la nación, además de señalar que el mantenimiento de los procesos ecológicos esenciales, la preservación de la diversidad genética y la utilización sostenida de las especies, de los ecosistemas y de los recursos naturales renovables en general son de carácter obligatorio (3).

El objetivo del presente trabajo es comparar la fórmula dentaria del canis familiaris con el odontograma del perro sin pelo del Perú, a fin de procurar un mejor conocimiento de sus características y grados de pureza, establecer parámetros para su selección y coadyuvar a su mejoramiento y conservación.

\section{MATERIAL Y MÉTODO}

\section{Metodología de trabajo}

El presente trabajo de investigación se realizó en la ciudad de Lima, durante el período que va de octubre de 2003 a febrero de 2004. Y lo primero que se hizo fue observar la cavidad oral para determinar la ausencia de dientes y registrar los datos en un odontograma (11).

Para la toma de muestra se solicitó al Kennel Club Peruano el registro de los perros sin pelo del Perú inscritos, y se seleccionó a los perros nacidos hasta octubre de 2002. Formaron la muestra todos los perros sin pelo del Perú mayores de un año, inscritos en la ciudad de Lima. El número de ejemplares de la muestra fue de 50.

Los perros fueron clasificados por sexo (machos y hembras) y por talla: pequeños ( 25 a 40 $\mathrm{cm})$, medianos ( $40 \mathrm{a} 50 \mathrm{~cm}$ ) y grandes $(50 \mathrm{a} 65$ $\mathrm{cm})$, a los cuales se asignó un código numérico. 
Los dientes fueron descritos según el sistema de identificación dental taquigráfico/anatómico, el mismo que consiste en asignar una letra a cada diente, según su función: $\mathrm{I}=$ incisivo, $\mathrm{C}=$ canino, $\mathrm{P}=$ premolar, $\mathrm{M}=$ molar. Cada cuadrante de la boca (superior, inferior, derecho e izquierdo) corresponde a cada esquina de la letra. Los dientes de los maxilares se designan con superíndices, y los dientes mandibulares, con subíndices. Los dientes se e numeran en forma consecutiva para cada tipo funcional a partir de la línea media; por ejemplo:

$$
\begin{aligned}
& \mathrm{I}^{2}=\text { segundo incisivo superior derecho. } \\
& { }_{3} \mathrm{P}=\text { tercer premolar inferior izquierdo. }
\end{aligned}
$$

Los datos fueron recolectados en unas "hojas de recolección de datos" especialmente diseñadas, en cuya parte superior se describe el código de cada perro, edad, sexo y tamaño. En la parte inferior se encuentra un odontograma en donde se registró con un círculo la ausencia de dientes.

Los datos fueron ordenados en unas "fichas de recopilación de datos" especialmente diseñadas, donde se describe de una manera más ordenada los dientes faltantes en cada perro, según su lado (derecho e izquierdo) y su plano (superior e inferior), determinando la ausencia con el número 1 .

El análisis de los datos se realizó valiéndonos de la estadística descriptiva. Se analizaron el número y porcentaje de dientes ausentes, de acuerdo a la talla el sexo, así como qué dientes son los más y menos comprometidos de acuerdo a su ubicación (planos derecho, izquierdo, superior e inferior). Se obtuvieron promedios de acuerdo al sexo y a la talla, sumando los datos obtenidos y dividiéndolos entre el número de perros:

$\sum$ de datos obtenidos

Número de perros muestreados

\section{RESULTADO}

\section{Número total de dientes ausentes por perro}

Se encontró la ausencia de 22 dientes ( $52 \%$ ) en 6 perros ( $12 \%)$, de los que 4 fueron machos y 2 fueron hembras, 5 de talla mediana y uno de talla pequeña. Una ausencia de 19 dientes (43\%) se verificó en 5 perros (10\%), de los cuales 4 fueron machos y uno fue hembra, 3 de talla grande y 2 de talla mediana. Asimismo se encontró la ausencia de 18 dientes en 5 perros (10\%), de los que 1 fue macho y 4 fueron hembras, dos de talla grande, dos medianos y uno pequeño. Con 16 dientes ausentes (19\%) se encontraron 4 perros $(8 \%)$, de los cuales todos fueron hembras de talla mediana.

Tres grupos de 3 perros (6\%) carecieron cada uno de $30(71 \%), 26(62 \%)$ y 20 (48\%) dientes respectivamente. De estos 9 perros, 4 fueron machos y 5 hembras, todos de talla mediana.

En 7 grupos de 2 perros ( $4 \%$ ) se halló la ausencia de 25 (60\%), 21 (50\%), 15 (36\%), 14 (33\%), 13 (31\%), 10 (24\%) y 4 (10\%) dientes respectivamente. De estos 14 perros, 3 fueron machos y 11 hembras, 13 de talla mediana y 1 de talla pequeña.

Por último, se observaron 7 grupos de 1 perro $(2 \%)$ en los que se verificó la ausencia de 27 (64\%), 24 (57\%), 17 (40\%), 11 (26\%), $9(21 \%), 7(17 \%)$ y $5(12 \%)$ dientes respectivamente. De estos 7 perros, 3 fueron machos y 4 fueron hembras, 1 de talla chica, 1 de talla grande y 5 de talla mediana (Tabla 1 )

Número total de dientes ausentes según su ubicación

\section{Maxilar}

Es conveniente señalar que el maxilar normalmente presenta 20 dientes. $\mathrm{Al}$ respecto, se 
Tabla 1. Dientes ausentes en el perro sin pelo del Perú con respecto a la fórmula dentaria del Canis familiaris (42 dientes)

\begin{tabular}{|c|c|c|c|c|c|c|c|c|c|}
\hline \multirow{3}{*}{$\begin{array}{c}\text { DIENTES } \\
\text { AUSENTES }\end{array}$} & \multirow{3}{*}{ PERROS } & \multirow{2}{*}{\multicolumn{2}{|c|}{ SEXO }} & \multirow{2}{*}{\multicolumn{3}{|c|}{ TALLA }} & \multicolumn{3}{|c|}{ EDAD } \\
\hline & & & & & & & \multirow{2}{*}{$\begin{array}{c}1-4 \\
\text { años }\end{array}$} & \multirow{2}{*}{$\frac{4-8}{4 \text { años }}$} & \multirow{2}{*}{$\frac{8-12}{\frac{8 \text { años }}{4}}$} \\
\hline & & Macho & Hembra & Grande & Mediano & Chico & & & \\
\hline $30(71,4 \%)$ & $3(6 \%)$ & 2 & 1 & 0 & 3 & 0 & 0 & 3 & 0 \\
\hline $27(64,2 \%)$ & $1(2 \%)$ & 1 & 0 & 0 & 1 & 0 & 0 & 1 & 0 \\
\hline $26(61,9 \%)$ & $3(6 \%)$ & 1 & 2 & 0 & 3 & 0 & 1 & 1 & 1 \\
\hline $25(59,5 \%)$ & $2(4 \%)$ & 0 & 2 & 0 & 2 & 0 & 1 & 1 & 0 \\
\hline $24(57,1 \%)$ & $1(2 \%)$ & 0 & 1 & 0 & 1 & 0 & 1 & 0 & 0 \\
\hline $22(52,3 \%)$ & $6(12 \%)$ & 4 & 2 & 0 & 5 & 1 & 2 & 2 & 2 \\
\hline $21(50 \%)$ & $2(4 \%)$ & 0 & 2 & 0 & 2 & 0 & 2 & 0 & 0 \\
\hline $20(47,6 \%)$ & $3(6 \%)$ & 1 & 2 & 0 & 3 & 0 & 1 & 2 & 0 \\
\hline $19(45,2 \%)$ & $5(10 \%)$ & 4 & 1 & 3 & 2 & 0 & 3 & 2 & 0 \\
\hline $18(42,8 \%)$ & $5(10 \%)$ & 1 & 4 & 2 & 2 & 1 & 3 & 2 & 0 \\
\hline $17(40,4 \%)$ & $1(2 \%)$ & 1 & 0 & 0 & 1 & 0 & 0 & 0 & 1 \\
\hline $16(38 \%)$ & $4(8 \%)$ & 0 & 4 & 0 & 4 & 0 & 3 & 1 & 0 \\
\hline $15(35,7 \%)$ & $2(4 \%)$ & 1 & 1 & 0 & 1 & 1 & 2 & 0 & 0 \\
\hline $14(33,3 \%)$ & $2(4 \%)$ & 1 & 1 & 0 & 2 & 0 & 2 & 0 & 0 \\
\hline $13(30,9 \%)$ & $2(4 \%)$ & 1 & 1 & 0 & 2 & 0 & 2 & 0 & 0 \\
\hline $11(26,19 \%)$ & $1(2 \%)$ & 0 & 1 & 1 & 0 & 0 & 1 & 0 & 0 \\
\hline $10(23,8 \%)$ & $2(4 \%)$ & 0 & 2 & 0 & 2 & 0 & 2 & 0 & 0 \\
\hline $9(21,4 \%)$ & $1(2 \%)$ & 0 & 1 & 0 & 0 & 1 & 1 & 0 & 0 \\
\hline $7(16,6 \%)$ & $1(2 \%)$ & 0 & 1 & 0 & 1 & 0 & 1 & 0 & 0 \\
\hline $5(11,9 \%)$ & $1(2 \%)$ & 1 & 0 & 0 & 1 & 0 & 1 & 0 & 0 \\
\hline $4(9,5 \%)$ & $2(4 \%)$ & 0 & 2 & 0 & 2 & 0 & 1 & 1 & 0 \\
\hline & $50(100 \%)$ & 19 & 31 & 6 & 40 & 4 & 30 & 16 & 4 \\
\hline
\end{tabular}

obtuvieron los resultados que se exponen a continuación.

En 12 perros $(24 \%)$ se encontró la ausencia de 10 dientes, representando esto un $50 \%$ de ausencia. En 7 casos (14\%) se verificó la ausencia de 12 dientes, lo que representa un $60 \%$ de ausencia. Del mismo modo, 6 perros $(12 \%)$ evidenciaron la ausencia de 8 dientes, constituyendo ello un $40 \%$ de ausencia.

En 5 grupos de 3 perros $(6 \%)$, la ausencia fue de 14 (70\%), 7 (35\%), 6 (30\%), 9 (45\%) y 5 (25\%) dientes respectivamente. Cuatro grupos de 2 perros carecían cada uno de 4 (20\%), $11(55 \%), 13(65 \%)$ y $3(15 \%)$ dientes respectivamente (Tabla 2 ).
Tabla 2. Número y porcentaje de dientes ausentes en el maxilar respecto a la fórmula dentaria del Canis familiaris (20 dientes)

\begin{tabular}{ccrr}
\hline DIENTES & AUSENTES & \multicolumn{2}{c}{ PERROS } \\
\hline 14 & $70 \%$ & 3 & $6 \%$ \\
13 & $65 \%$ & 2 & $4 \%$ \\
12 & $60 \%$ & 7 & $14 \%$ \\
11 & $55 \%$ & 2 & $4 \%$ \\
10 & $50 \%$ & 2 & $24 \%$ \\
9 & $45 \%$ & 3 & $6 \%$ \\
8 & $40 \%$ & 6 & $12 \%$ \\
7 & $35 \%$ & 3 & $6 \%$ \\
6 & $30 \%$ & 3 & $6 \%$ \\
5 & $25 \%$ & 3 & $6 \%$ \\
4 & $20 \%$ & 2 & $4 \%$ \\
3 & $15 \%$ & 2 & $4 \%$ \\
2 & $10 \%$ & 1 & $2 \%$ \\
\hline 1 & $5 \%$ & 1 & $2 \%$ \\
\hline
\end{tabular}




\section{Mandibula}

La mandíbula normalmente presenta 22 dientes. Los resultados obtenidos se describen a continuación.

En 10 perros (20\%) se halló la ausencia de 10 dientes, lo que representa un $46 \%$ de ausencia. En 6 casos (12\%) se verificó la ausencia de 9 dientes, lo que significa un $41 \%$ de ausencia dental.

Del mismo modo se encontraron 2 grupos de 5 perros $(12 \%)$ con $14(64 \%)$ y $6(27 \%)$ dientes ausentes. En 2 grupos de 4 perros $(8 \%)$ se encontraron $12(55 \%)$ y 7 (32\%) dientes ausentes. En 3 perros $(6 \%)$ se verificó la ausencia de $8(36 \%)$ dientes. Cinco grupos de 2 perros $(4 \%)$ carecían de $16(72 \%), 13$ (59\%), 11 (50\%), 5 (23\%) y 3 (14\%) dientes respectivamente. Por último, se observaron 3 grupos de 1 perro $(2 \%)$ cada uno con $18(82 \%), 4(18 \%)$ y 1 (5\%) dientes ausentes (Tabla 3).

Tabla 3. Número y porcentaje de dientes ausentes en la mandíbula respecto a la fórmula dentaria del Canis familiaris (22 dientes)

\begin{tabular}{|c|c|c|c|}
\hline \multicolumn{2}{|c|}{ PERROS } & \multicolumn{2}{c|}{ AUSENCIA DE DIENTES } \\
\hline $\mathbf{N}^{\circ}$ & $\%$ & No DE DIENTES $^{\circ}$ & $\%$ \\
\hline 18 & 81,8 & 1 & 2 \\
\hline 16 & 72,7 & 2 & 4 \\
\hline 14 & 63,6 & 5 & 10 \\
\hline 13 & 59 & 2 & 4 \\
\hline 12 & 54,5 & 4 & 8 \\
\hline 11 & 50 & 2 & 4 \\
\hline 10 & 45,4 & 10 & 20 \\
\hline 9 & 40,9 & 6 & 12 \\
\hline 8 & 36,3 & 3 & 6 \\
\hline 7 & 31,8 & 4 & 8 \\
\hline 6 & 27,2 & 5 & 10 \\
\hline 5 & 22,7 & 2 & 4 \\
\hline 4 & 18,1 & 1 & 2 \\
\hline 3 & 13,6 & 2 & 4 \\
\hline 1 & 4,5 & 1 & 100 \\
\hline TOTAL & 50 & \\
\hline
\end{tabular}

Número total de dientes ausentes según sexo

Debemos señalar que de un total de 50 perros tomados como muestra, se encontraron 19 machos y 31 hembras, cuyos resultados en cuanto a la dentición exponemos a continuación.

\section{Maxilar}

En el caso de las hembras, 5 perros (16,12\%) presentaron ausencia de 10 dientes, representando esto un $50 \%$ de ausencia. En 2 grupos de 4 perros $(12,90 \%)$ se observó la ausencia de 8 (40\%) y $12(60 \%)$ dientes respectivamente. Del mismo modo, se verificó que tres perros $(9,67 \%)$ carecían de 6 dientes, lo que representa un $30 \%$ de ausencia. En 6 grupos de 2 perros $(6,45 \%)$ se hallaron $14(70 \%), 9$ (45\%), 7 (35\%), 5 (25\%), $4(20 \%)$ y $3(15 \%)$ dientes ausentes, respectivamente. Por último, 3 grupos de 1 perro $(3,22 \%)$ carecían respectivamente de 13 (65\%), 11 (55 $\%)$ y $1(5 \%)$ dientes.

Por otro lado, en los machos se encontró que 7 perros $(36,84 \%)$ carecían de 10 dientes, lo que representa un $50 \%$ de ausencia. Tres perros $(15,78 \%)$ mostraron la ausencia de 12 dientes, lo que significa un $60 \%$ de ausencia. Dos perros $(10,52 \%)$ mostraron una ausencia de 8 dientes, lo que constituye un $40 \%$ de ausencia. Finalmente, se observaron 7 grupos de 1 perro $(5,26$ $\%)$, cada uno con 14 (70\%), 13 (65\%), 11 (55 $\%), 9(45 \%), 7$ (35\%), 5 (25\%) y 2 ( $10 \%)$ dientes ausentes respectivamente (Tabla 4$)$.

\section{Mandibula}

En el caso de las hembras, 7 perros (22,58 \%) evidenciaron la ausencia de 10 dientes, lo que representa un $45 \%$ de ausencia. En 5 perros (16,12 $\%)$ se halló la ausencia de 6 dientes, lo que significa un $27 \%$ de ausencia. Del mismo modo, 3 perros $(9,67 \%)$ mostraron la ausencia de 14 dientes, lo que constituye una ausencia de $64 \%$. Cinco grupos de 2 perros $(6,45 \%)$ mostraron 


\section{Tabla 4. Número y porcentaje de dientes ausentes en el maxilar por sexo}

\begin{tabular}{c|r|r|r|r|r|r|r|}
\multicolumn{5}{c}{ HEMBRAS } & \multicolumn{5}{c|}{ MACHOS } \\
\hline Dientes ausentes & $\%$ & Perros & \multicolumn{1}{c|}{$\%$} & Dientes ausentes & $\%$ & Perros & $\%$ \\
\hline 14 & 70 & 2 & 6,45 & 14 & 70 & 1 & 5,26 \\
\hline 13 & 65 & 1 & 3,23 & 13 & 65 & 1 & 5,26 \\
\hline 12 & 60 & 4 & 12,90 & 12 & 60 & 3 & 15,79 \\
\hline 11 & 55 & 1 & 3,23 & 11 & 55 & 1 & 5,26 \\
\hline 10 & 50 & 5 & 16,13 & 10 & 50 & 7 & 36,84 \\
9 & 45 & 2 & 6,45 & 9 & 45 & 1 & 5,26 \\
\hline 8 & 40 & 4 & 12,90 & 8 & 40 & 2 & 10,53 \\
7 & 35 & 2 & 6,45 & 7 & 35 & 1 & 5,26 \\
\hline 6 & 30 & 3 & 9,67 & 5 & 25 & 1 & 5,26 \\
\hline 5 & 25 & 2 & 6,45 & 2 & 10 & 1 & 5,26 \\
\hline 4 & 20 & 2 & 6,45 & - & - & - & - \\
\hline 3 & 15 & 2 & 6,45 & - & - & - & - \\
\hline 1 & 5 & 1 & 3,23 & - & - & - & - \\
\hline TOTAL & & 31 & 100 & & & 19 & 100 \\
\hline
\end{tabular}

la ausencia de 13 (60\%), 11 (50\%), 8 (36\%), $9(41 \%)$ y $5(23 \%)$ dientes respectivamente.

De otro lado, en el caso de los machos, se encontraron 4 perros $(21,05 \%)$ que mostraban una ausencia de 9 dientes, lo que representa un $41 \%$. Tres grupos de 3 perros $(15,78 \%)$ tenían
$12(55 \%), 10(45 \%)$ y 17 (32\%) dientes ausentes respectivamente. Asimismo, se encontraron 2 perros $(10,52 \%)$ con 14 dientes ausentes, constituyendo $14 \%$ de ausencia. Por último, se observaron 4 grupos de 1 perro $(5,26 \%)$, cada uno con $18(82 \%), 16(73 \%), 8(36 \%)$ y $3(14 \%)$ dientes ausentes respectivamente (Tabla 5$)$.

Tabla 5. Número y porcentaje de dientes ausentes en la mandíbula por sexo

\begin{tabular}{|c|r|r|r|r|r|r|r|}
\hline \multicolumn{4}{c}{ HEMBRAS } & \multicolumn{5}{c|}{ MACHOS } \\
\hline Dientes ausentes & $\%$ & Perros & $\%$ & Dientes ausentes & $\%$ & Perros & $\%$ \\
\hline 16 & 72,7 & 1 & 3,23 & 18 & 81,8 & 1 & 5,26 \\
14 & 63,6 & 3 & 9,67 & 16 & 72,7 & 1 & 5,26 \\
\hline 13 & 59 & 2 & 6,45 & 14 & 63,6 & 2 & 10,53 \\
12 & 54,5 & 1 & 3,23 & 12 & 54,5 & 3 & 15,79 \\
\hline 11 & 50 & 2 & 6,45 & 10 & 45,4 & 3 & 15,79 \\
10 & 45,4 & 7 & 22,58 & 9 & 40,9 & 4 & 21,05 \\
\hline 9 & 40,9 & 2 & 6,45 & 8 & 36,3 & 1 & 5,26 \\
8 & 36,3 & 2 & 6,45 & 7 & 31,8 & 3 & 15,79 \\
\hline 7 & 31,8 & 1 & 3,23 & 3 & 13,6 & 1 & 5,26 \\
\hline 6 & 27,2 & 5 & 16,13 & - & - & - & - \\
\hline 5 & 22,7 & 2 & 6,45 & - & - & - & - \\
4 & 18,1 & 1 & 3,23 & - & - & - & - \\
\hline 3 & 13,6 & 1 & 3,23 & - & - & - & - \\
\hline 1 & 4,5 & 1 & 3,23 & - & - & - & - \\
\hline TOTAL & & 31 & 100 & & & 19 & 100 \\
\hline
\end{tabular}


Número total de dientes ausentes según talla

Es conveniente mencionar que en la raza del perro sin pelo del Perú existen tres tallas. En la muestra tomada se encontraron 40 perros de talla mediana, 6 de talla grande y 4 de talla chica. Debido a que el número de ejemplares de las tallas grande y chica es pequeño, describiremos solo los datos encontrados en los ejemplares de talla mediana.

\section{Maxilar}

En 10 perros $(25 \%)$ se halló la carencia de 10 dientes, lo que constituye un $50 \%$ de ausencia. En 5 casos (12,5\%) encontramos la falta de 12 dientes, lo que constituye un $60 \%$ de ausencia. Del mismo modo, se encontraron 4 grupos de 3 perros (7,5\%), cada uno con 14 (70\%), 8 (40\%), 7 (35\%) y 6 (30\%) dientes ausentes respectivamente, En 5 grupos de 2 perros $(5 \%)$ se halló la ausencia de 13 (65\%), 11 (55\%), 9 (45
\%), 5 (25\%) y $3(15 \%)$ dientes ausentes respectivamente. Por último, se observaron tres grupos de un perro (2,5\%), cada uno con 4 (20\%), 2 $(10 \%)$ y $1(5 \%)$ dientes ausentes respectivamente.

\section{Mandibula}

En 6 perros (15\%) se notó la falta de 10 dientes, lo que representa un $46 \%$ de ausencia. En 5 perros (12,5\%) se verificó la ausencia de 14 dientes, lo que significa un $64 \%$ de ausencia. En 2 grupos de 4 perros $(10 \%)$ se encontró la carencia de $12(55 \%)$ y 9 (41\%) dientes respectivamente. En 3 grupos de 3 perros $(7,5 \%)$ se halló la ausencia de 8 (36\%), 7 (32\%) y 6 (27\%) dientes respectivamente. En 4 grupos de 2 perros $(5 \%)$ hallamos la ausencia de 16 (73\%), 13 (59\%), $11(50 \%)$ y $3(14 \%)$ dientes respectivamente. Finalmente, se encontraron 5 grupos de 1 perro $(2,5 \%)$, cada uno de los cuales carecían de 18 (82 $\%), 5(23 \%), 4(18 \%)$ y 1 (5\%) dientes respectivamente (Tabla 6).

Tabla 6. Número y porcentaje de dientes ausentes en perros de talla mediana

\begin{tabular}{c|c|r|r|r|r|r|r}
\multicolumn{4}{c}{ MAXILAR } & \multicolumn{5}{c|}{ MANDíBULA } \\
\hline Dientes ausentes & $\%$ & Perros & \multicolumn{1}{c|}{$\%$} & Dientes ausentes & $\%$ & Perros & $\%$ \\
\hline 14 & 70 & 3 & 7,5 & 18 & 81,8 & 1 & 2,5 \\
13 & 65 & 2 & 5,0 & 16 & 72,7 & 2 & 5,0 \\
\hline 12 & 60 & 5 & 12,5 & 14 & 63,6 & 5 & 12,5 \\
11 & 55 & 2 & 5,0 & 13 & 59,0 & 2 & 5,0 \\
\hline 10 & 50 & 10 & 25,0 & 12 & 54,5 & 4 & 10,0 \\
\hline 9 & 45 & 2 & 5,0 & 11 & 50,0 & 2 & 5,0 \\
\hline 8 & 40 & 3 & 7,5 & 10 & 45,4 & 6 & 15,0 \\
7 & 35 & 3 & 7,5 & 9 & 40,9 & 4 & 10,0 \\
\hline 6 & 30 & 3 & 7,5 & 8 & 36,3 & 3 & 7,5 \\
\hline 5 & 25 & 2 & 5,0 & 7 & 31,8 & 3 & 7,5 \\
\hline 4 & 20 & 1 & 2,5 & 6 & 27,2 & 3 & 7,5 \\
\hline 3 & 15 & 2 & 5,0 & 5 & 22,7 & 1 & 2,5 \\
\hline 2 & 10 & 1 & 2,5 & 4 & 18,1 & 1 & 2,5 \\
\hline 1 & 5 & 1 & 2,5 & 3 & 13,6 & 2 & 5,0 \\
\hline- & - & - & - & 1 & 4,5 & 1 & 2,5 \\
\hline TOTAL & & 40 & 100 & & & 40 & 100 \\
\hline
\end{tabular}


Ausencia según el tipo de diente

En el maxilar derecho se encontró que el primer y segundo incisivos estaban ausentes en 14 perros $(28 \%)$, mientras que el tercer diente faltaba en 21 perros (42\%). El primer y segundo incisivo maxilar izquierdo se hallaba ausente en 11 perros ( $22 \%)$, en tanto que el tercer incisivo faltaba en 22 perros (44\%).

El canino del maxilar derecho estaba ausente en 32 perros (64\%), y en el maxilar izquierdo el canino faltaba en 29 perros (58\%). En el maxilar derecho faltaban el primer, segundo, tercer y cuarto premolares en 34 (58\%), 31 (62\%), 38 (76\%) y $6(12 \%)$ casos respectivamente. En el maxilar izquierdo, el primer, segundo, tercer y cuarto premolar estaban ausentes en 31 (62\%), 34 (68\%), $36(72 \%)$ y $3(6 \%)$ perros respectivamente.

En el maxilar derecho se observó la ausencia del primer y segundo molar en 15 (30\%) y 28 (56\%) perros respectivamente, en tanto que en el maxilar izquierdo faltaron el primer y segundo molar en $9(18 \%)$ y $25(50 \%)$ perros respectivamente.
Por otra parte, en la mandíbula derecha faltó el primer incisivo en 17 (34\%) perros, el segundo en 8 ( $16 \%)$ perros y el tercero en 6 (12\%) perros. En la mandíbula izquierda no existían el primer, segundo y tercer incisivos en $20(40 \%), 6(12 \%)$ y $8(16 \%)$ perros respectivamente.

El canino mandibular derecho estuvo ausente en 28 (56\%) casos; asimismo, el izquierdo estuvo ausente en 23 ( $46 \%$ ) perros. Con respecto a los premolares, en el lado mandibular derecho se notó la ausencia del primer, segundo, tercer y cuarto premolares en 30 (60\%), 41 (82\%), 40 (80\%) y $39(78 \%)$ perros respectivamente. En el lado izquierdo, estos dientes faltaron en 35 (70 $\%), 41(82 \%), 42(84 \%)$ y 40 (80\%) perros respectivamente.

El primer molar de ambas mandíbulas estuvo presente en todos los casos. El segundo y tercer molar del lado mandibular derecho estuvieron ausentes en 7 (14\%) y 20 (40\%) perros respectivamente. Del mismo modo, en el lado izquierdo, estos dientes faltaron en $4(8 \%)$ y $18(36 \%)$ casos respectivamente (Tabla 7$)$.

Tabla 7. Número y porcentaje de ausencia según el tipo de diente

\begin{tabular}{|c|c|c|c|c|c|c|c|c|}
\hline \multirow{3}{*}{ DIENTES } & \multicolumn{4}{|c|}{ MAXILAR } & \multicolumn{4}{|c|}{ MANDÍBULA } \\
\hline & \multicolumn{2}{|c|}{ Derecho } & \multicolumn{2}{|c|}{ Izquierdo } & \multicolumn{2}{|c|}{ Derecha } & \multicolumn{2}{|c|}{ Izquierda } \\
\hline & $\mathbf{N}^{\circ}$ & $\%$ & $\mathbf{N}^{\circ}$ & $\%$ & $\mathbf{N}^{\circ}$ & $\%$ & $\mathbf{N}^{\circ}$ & $\%$ \\
\hline 1er. incisivo & 14 & 28 & 11 & 22 & 17 & 34 & 20 & 40 \\
\hline 2do. incisivo & 14 & 28 & 11 & 22 & 8 & 16 & 6 & 12 \\
\hline 3er. incisivo & 21 & 42 & 22 & 44 & 6 & 12 & 8 & 16 \\
\hline Canino & 32 & 64 & 29 & 58 & 28 & 56 & 23 & 46 \\
\hline 1er. premolar & 34 & 68 & 31 & 62 & 30 & 60 & 35 & 70 \\
\hline 2do. premolar & 31 & 62 & 34 & 68 & 41 & 82 & 41 & 82 \\
\hline 3er. premolar & 38 & 76 & 36 & 72 & 40 & 80 & 42 & 84 \\
\hline 4to. premolar & 6 & 12 & 3 & 6 & 39 & 78 & 40 & 80 \\
\hline 1er. molar & 15 & 30 & 9 & 18 & 0 & 0 & 0 & 0 \\
\hline 2do. molar & 28 & 56 & 25 & 50 & 7 & 14 & 4 & 8 \\
\hline 3er. molar* & - & - & - & - & 20 & 40 & 18 & 36 \\
\hline
\end{tabular}

*El maxilar no presenta tercer premolar. 
Tipo de diente ausente según el sexo

\section{Maxilar}

\section{Machos}

En 3 grupos de 7 perros (37\%) se observó la ausencia del primer, segundo y tercer incisivos del lado derecho respectivamente. En 2 grupos de 6 perros $(32 \%)$ faltaron el primer y segundo incisivos del lado izquierdo respectivamente. En 9 perros (47\%) no se observó el tercer incisivo del lado izquierdo.

El canino derecho estuvo ausente en $13 \mathrm{ca}-$ sos (68\%), y el izquierdo en 12 casos (63\%). Se observó la ausencia del primer, segundo, tercer y cuarto premolares del lado derecho en 12 (63\%), $13(68 \%), 14(74 \%)$ y $2(11 \%)$ perros respectivamente, mientras el primer premolar izquierdo faltó en 15 perros $(79 \%)$. El segundo y tercer premolares del lado izquierdo estuvieron ausentes en 14 casos (74\%). El cuarto premolar estuvo presente en todos los perros machos de la muestra.

El primer y segundo molares del lado derecho faltaron en 7 (37\%) y $13(68 \%)$ perros respectivamente. El primer y segundo molares del lado izquierdo estuvieron ausentes en $3(16 \%)$ y 9 (47\%) perros respectivamente (Tabla 8 ).

\section{Hembras}

El primer y segundo incisivos del lado derecho estuvieron ausentes en 7 casos (23\%), y estos mismos dientes del lado izquierdo faltaron en 5 perros (16\%). El tercer incisivo derecho no estuvo presente en 14 perros ( $45 \%$ ), y en el lado izquierdo faltó en 13 casos (42\%).

El canino derecho y el canino izquierdo estuvieron ausentes en 19 (61\%) y $17(55 \%)$ perros respectivamente. El primer, segundo, tercer y cuarto premolares del lado derecho faltaron en 22 (71\%), 18 (58 \%), 24 (77\%) y 4 (13\%) perros respectivamente. El primer, segundo, tercer y cuarto premolares del lado izquierdo estuvieron ausentes en $16(52 \%), 20$ (65\%), 22 (71\%) y $3(10 \%)$ casos respectivamente.

El primer molar y el segundo molar del lado derecho no se observaron en $8(26 \%)$ y 15 (48\%) perros respectivamente. En el lado izquierdo, el primer molar estuvo ausente en 6 perros (19\%), mientras el segundo faltó en 16 perros (52\%) (Tabla 8).

Tabla 8. Tipo de diente ausente en el maxilar según sexo: $\operatorname{machos}(\mathrm{n}=19)$ y hembras $(\mathrm{n}=31)$

\begin{tabular}{|c|c|c|c|c|c|c|c|c|}
\hline \multirow{3}{*}{ DIENTES } & \multicolumn{4}{|c|}{ DRECHO } & \multicolumn{4}{|c|}{ IZQUIERDO } \\
\hline & \multicolumn{2}{|c|}{ Macho } & \multicolumn{2}{|c|}{ Hembra } & \multicolumn{2}{|c|}{ Macho } & \multicolumn{2}{|c|}{ Hembra } \\
\hline & $\mathbf{N}^{\circ}$ & $\%$ & $\mathbf{N}^{\circ}$ & $\%$ & $\mathrm{~N}^{\circ}$ & $\%$ & $\mathbf{N}^{\circ}$ & $\%$ \\
\hline 1er. incisivo & 7 & 37 & 7 & 23 & 6 & 32 & 5 & 16 \\
\hline 2 do. incisivo & 7 & 37 & 7 & 23 & 6 & 32 & 5 & 16 \\
\hline 3er. incisivo & 7 & 37 & 14 & 45 & 9 & 47 & 13 & 42 \\
\hline Canino & 13 & 68 & 19 & 61 & 12 & 63 & 17 & 55 \\
\hline 1er. premolar & 12 & 63 & 22 & 71 & 15 & 79 & 16 & 52 \\
\hline 2do. premolar & 13 & 68 & 18 & 58 & 14 & 74 & 20 & 65 \\
\hline 3er. premolar & 14 & 74 & 24 & 77 & 14 & 74 & 22 & 71 \\
\hline 4to. premolar & 2 & 11 & 4 & 13 & 0 & 0 & 3 & 10 \\
\hline 1er. molar & 7 & 37 & 8 & 26 & 3 & 16 & 6 & 19 \\
\hline 2do. molar & 13 & 68 & 15 & 48 & 9 & 47 & 16 & 52 \\
\hline
\end{tabular}




\section{Mandibula}

Machos

En el lado derecho se observó que el primer incisivo estuvo ausente en 9 perros $(47 \%)$, el segundo incisivo faltó en 5 perros (26\%), y el tercero en 2 perros (11\%), mientras que en el lado izquierdo se observó que el primer, segundo y tercer incisivos faltaron en 12 (63\%), 2 (11\%) y $4(21 \%)$ perros respectivamente.

El canino derecho e izquierdo estuvieron ausentes respectivamente en 2 grupos de 8 ( $42 \%$ ) perros. En el lado derecho faltaron el primer premolar en 11 perros (58\%), el segundo y cuarto premolares faltaron cada uno en 15 perros (79\%), mientras el tercer premolar estuvo ausente en 14 perros (74\%). En el lado izquierdo, el primer premolar no estuvo presente en 16 perros (84\%), el segundo y cuarto premolar faltaron cada uno en 17 perros ( $89 \%$ ), y el tercer premolar no se observó en 18 perros (95\%).

El primer molar derecho y el primer molar izquierdo estuvieron presentes en todos los casos considerados de la muestra. El segundo y tercer molares del lado derecho faltaron en $2(11 \%)$ y
$12(63 \%)$ perros respectivamente, mientras en el lado izquierdo estos dientes faltaron en $1(5 \%)$ y $8(42 \%)$ perros respectivamente (Tabla 9$)$.

\section{Hembras}

El primer incisivo derecho y el primer incisivo izquierdo estuvieron ausentes en 8 perros (26\%). El segundo incisivo derecho faltó en 3 perros $(10 \%)$, mientras el segundo incisivo izquierdo faltó en 4 perros (13\%).

El canino derecho estuvo ausente en 20 perros (65\%), y el izquierdo, en 15 perros (48\%). El primer premolar del lado derecho y el del lado izquierdo faltaron respectivamente en 2 grupos de 19 perros (61\%). El segundo y el tercer premolares del lado derecho faltaron en 26 perros (84\%); de igual manera, estos mismos premolares del lado izquierdo estuvieron ausentes en 24 perros $(77 \%)$. Por último, el cuarto premolar derecho no se observó en 24 perros (77\%), mientras en el lado izquierdo faltó en 23 perros $(74 \%)$.

El primer molar derecho y el primer molar izquierdo estuvieron presentes en todos los casos. El segundo y tercer molares del lado derecho

Tabla 9. Tipo de diente ausente en la mandíbula según sexo: $\operatorname{machos}(\mathrm{n}=19)$ y hembras $(\mathrm{n}=31)$

\begin{tabular}{|c|c|c|c|c|c|c|c|c|}
\hline \multirow{3}{*}{ DIENTES } & \multicolumn{4}{|c|}{ DERECHA } & \multicolumn{4}{|c|}{ IZQUIERDA } \\
\hline & \multicolumn{2}{|c|}{ Macho } & \multicolumn{2}{|c|}{ Hembra } & \multicolumn{2}{|c|}{ Macho } & \multicolumn{2}{|c|}{ Hembra } \\
\hline & $\mathbf{N}^{\circ}$ & $\%$ & $\mathbf{N}^{o}$ & $\%$ & $\mathbf{N}^{\circ}$ & $\%$ & $\mathbf{N}^{o}$ & $\%$ \\
\hline 1er. incisivo & 9 & 47 & 8 & 26 & 12 & 63 & 8 & 26 \\
\hline 2 do. incisivo & 5 & 26 & 3 & 10 & 2 & 11 & 4 & 13 \\
\hline 3er. incisivo & 2 & 11 & 4 & 13 & 4 & 21 & 4 & 13 \\
\hline Canino & 8 & 42 & 20 & 65 & 8 & 42 & 15 & 48 \\
\hline 1er. premolar & 11 & 58 & 19 & 61 & 16 & 84 & 19 & 61 \\
\hline 2do. premolar & 15 & 79 & 26 & 84 & 17 & 89 & 24 & 77 \\
\hline 3er. premolar & 14 & 74 & 26 & 84 & 18 & 95 & 24 & 77 \\
\hline 4to. premolar & 15 & 79 & 24 & 77 & 17 & 89 & 23 & 74 \\
\hline 1er. molar & 0 & 0 & 0 & 0 & 0 & 0 & 0 & 0 \\
\hline 2do. molar & 2 & 11 & 5 & 16 & 1 & 5 & 3 & 10 \\
\hline 3er. molar & 12 & 63 & 8 & 26 & 8 & 42 & 10 & 32 \\
\hline
\end{tabular}


faltaron en $5(16 \%)$ y $8(26 \%)$ perros respectivamente. A su vez, en el lado izquierdo, estos molares faltaron en 3 (10\%) y 10 (32\%) perros respectivamente (Tabla 9).

\section{Tipo de diente ausente según la talla}

En este caso, nuevamente, debido a que los tamaños de las muestras de perros de talla grande y chica son pequeños, se describirán los datos encontrados solo en la talla mediana.

\section{Maxilar}

El primer incisivo derecho estuvo ausente en 13 perros (33\%), mientras en el lado izquierdo no se observó el primer incisivo en 10 perros $(25$ $\%)$. El segundo incisivo izquierdo y el segundo incisivo derecho estuvieron ausentes respectivamente en 2 grupos de 11 perros (28\%). Asimismo, el tercer incisivo izquierdo y el tercer incisivo derecho faltaron respectivamente en dos grupos de 17 perros ( $43 \%)$. El canino derecho estuvo ausente en 26 perros (65\%), y el izquierdo, en 23 perros $(58 \%)$.
El primer premolar derecho no se observó en 27 casos (68\%), mientras el izquierdo faltó en 26 perros $(65 \%)$. El segundo premolar derecho faltó en 23 perros ( $58 \%$ ), y el izquierdo, en 26 perros $(65 \%)$. El tercer premolar derecho no estuvo presente en 31 perros (78\%), y el izquierdo, en 29 perros (73\%). El cuarto premolar derecho faltó en 5 perros (13\%), y el izquierdo, en 3 pe$\operatorname{rros}(8 \%)$.

Finalmente, se observó la ausencia del primer molar derecho en 12 perros (30\%), y el izquierdo faltó en 8 perros $(20 \%)$. El segundo molar derecho estuvo ausente en 21 perros (53\%), y el izquierdo, en 19 perros (48\%) (Tabla 10).

\section{Mandibula}

El primer incisivo derecho faltó en 16 casos (40\%), y el izquierdo no se observó en 19 casos (48\%). El segundo incisivo del lado derecho estuvo ausente en 8 perros $(20 \%)$, mientras el del lado izquierdo faltó en 6 perros $(15 \%)$. La ausencia del tercer incisivo derecho se observó en 6 perros $(15 \%)$, en tanto que el tercer incisivo izquierdo faltó en 8 perros (20\%).

Tabla 10. Tipo de diente ausente en maxilar y mandíbula en la talla mediana

$$
(n=40)
$$

\begin{tabular}{|c|c|c|c|c|c|c|c|c|}
\hline \multirow{3}{*}{ DIENTES } & \multicolumn{4}{|c|}{ MAXILAR } & \multicolumn{4}{|c|}{ MANDÍBULA } \\
\hline & \multicolumn{2}{|c|}{ Derecho } & \multicolumn{2}{|c|}{ Izquierdo } & \multicolumn{2}{|c|}{ Derecha } & \multicolumn{2}{|c|}{ Izquierda } \\
\hline & $\mathbf{N}^{\circ}$ & $\%$ & $\mathbf{N}^{\circ}$ & $\%$ & No & $\%$ & No & $\%$ \\
\hline 1er. incisivo & 13 & 33 & 10 & 25 & 16 & 40 & 19 & 48 \\
\hline 2 do. incisivo & 11 & 28 & 11 & 28 & 8 & 20 & 6 & 15 \\
\hline 3er. incisivo & 17 & 43 & 17 & 43 & 6 & 15 & 8 & 20 \\
\hline Canino & $\begin{array}{l}26 \\
65\end{array}$ & 23 & 58 & 23 & 58 & $\begin{array}{l}20 \\
50\end{array}$ & & \\
\hline ler. premolar & 27 & 68 & 26 & 65 & 28 & 70 & 31 & 78 \\
\hline 2do. premolar & 23 & 58 & 26 & 65 & 31 & 78 & 32 & 80 \\
\hline 3er. premolar & 31 & 78 & 29 & 73 & 32 & 80 & 34 & 85 \\
\hline 4to. premolar & 5 & 13 & 3 & 8 & 30 & 75 & 32 & 80 \\
\hline 1er. molar & 12 & 30 & 8 & 20 & 0 & 0 & 0 & 0 \\
\hline 2do. molar & 21 & 53 & 19 & 48 & 4 & 10 & 4 & 10 \\
\hline 3er. molar* & - & - & - & - & 13 & 33 & 14 & 35 \\
\hline
\end{tabular}

*El maxilar no presenta tercer premolar. 
El canino derecho faltó en 23 perros (58\%), y el izquierdo, en 20 perros (50\%).

El primer, segundo, tercer y cuarto premolares del lado derecho faltaron en 28 (70\%), 31 (78\%), 32 (80\%), y 30 (75\%) perros respectivamente, mientras en el lado izquierdo el primer y segundo premolares estuvieron ausentes en 31 (78 $\%)$ y $34(85 \%)$ perros respectivamente, mientras el segundo y cuarto premolares faltaron respectivamente en 2 grupos de 32 perros (80\%).

El primer molar derecho y el primer molar izquierdo estuvieron siempre presentes en todos los perros de la muestra, representando esto un $0 \%$ de ausencia. El segundo molar derecho y el segundo molar izquierda faltaron en 4 perros (10\%). Finalmente, faltó el tercer molar derecho en 13 perros (33\%), y el tercer molar izquierdo, en 14 perros (35\%) (Tabla 10).

\section{Diente persistente}

En la muestra, de 50 perros, se encontró que 15 de ellos presentaban una persistencia de caninos de leche, lo que describimos a continuación.

\section{Tabla 11. Perros con persistencia de caninos de} leche

\begin{tabular}{|c|c|c|c|c|}
\hline PERROS & $\begin{array}{c}\text { CANINOS } \\
\text { PERSISTENTES }\end{array}$ & SEXO & TALLA & EDAD \\
\hline $\mathrm{O} 30$ & 4 & M & M & 1 \\
\hline O36 & 3 & $\mathrm{H}$ & $\mathrm{M}$ & 1 \\
\hline O31 & 2 & M & M & 1 \\
\hline O24 & 2 & $\mathrm{H}$ & M & 2 \\
\hline $\mathrm{O} 27$ & 2 & $\mathrm{H}$ & M & 2,5 \\
\hline O34 & 2 & $\mathrm{H}$ & M & 3 \\
\hline O35 & 2 & $\mathrm{H}$ & M & 1,2 \\
\hline O37 & 2 & $\mathrm{H}$ & G & 2,6 \\
\hline O41 & 2 & $\mathrm{H}$ & M & 4 \\
\hline $\mathrm{O} 17$ & 1 & M & $\mathrm{M}$ & 4 \\
\hline $\mathrm{O} 23$ & & M & M & 3 \\
\hline $\mathrm{O} 18$ & 1 & $\mathrm{H}$ & M & 2,5 \\
\hline O19 & 1 & $\mathrm{H}$ & M & 2 \\
\hline $\mathrm{O} 22$ & 1 & $\mathrm{H}$ & M & 2 \\
\hline O42 & 1 & $\mathrm{H}$ & G & 3,6 \\
\hline
\end{tabular}

Tabla 12. Perros con persistencia de caninos de leche según su ubicación

\begin{tabular}{|c|c|c|c|c|}
\multirow{2}{*}{ PERROS } & \multicolumn{2}{|c|}{ MAXILAR } & \multicolumn{2}{c}{ MANDíbULA } \\
\cline { 2 - 5 } O30 & 1 & 1 & 1 & 1 \\
O36 & 1 & 1 & 1 & \\
O31 & 1 & 1 & & \\
\hline O24 & 1 & 1 & & \\
\hline O27 & 1 & 1 & & \\
O34 & 1 & 1 & & \\
\hline O35 & 1 & 1 & & \\
\hline O37 & & & 1 & 1 \\
\hline O41 & 1 & 1 & & \\
\hline O17 & & & 1 & \\
\hline O23 & & 1 & & \\
\hline O18 & 1 & & & \\
\hline O19 & & 1 & & \\
\hline O22 & 1 & & & \\
\hline O42 & 1 & & & \\
\hline TOTAL & $\mathbf{1 1}$ & $\mathbf{1 0}$ & $\mathbf{4}$ & $\mathbf{2}$ \\
\hline
\end{tabular}

Se encontró un perro con los cuatro caninos persistentes, un perro con 3 caninos persistentes y 7 casos con persistencia de 2 caninos. De los 15 casos, 4 perros eran machos y 11 hembras, 13 de los cuales eran de talla mediana y solo 2 eran de raza grande. Con respecto a la edad, los perros iban de 1 a cuatro años (Tabla 11).

Respecto de su ubicación, se observó que el canino de leche del maxilar derecho estuvo presente en 11 perros, en tanto que el canino de leche del maxilar izquierdo estuvo presente en 10 perros. Por su lado, el canino de leche de la mandíbula derecha estuvo presente en 4 casos, en tanto que el de la mandíbula izquierda lo estuvo en 2 casos (Tabla 12).

\section{DISCUSIÓN}

En la presente investigación se ha comparado la fórmula dentaria del Canis familiaris con el odontograma del perro sin pelo del Perú, para 
lo cual se tomaron 50 perros de esta raza. Al no existir trabajos sobre esta raza con los cuales comparar los resultados obtenidos, pasamos a continuación a la interpretación de los datos obtenidos.

De un total de 50 perros de la muestra, se encontraron 3 perros con 30 dientes ausentes, siendo este el máximo de dientes faltantes ( 71 $\%)$, y como mínimo se encontraron 2 perros con 4 dientes ausentes (10\%).

En el maxilar se halló como máximo 14 dientes $(70 \%)$ ausentes en 3 perros, y como mínimo se observó 1 perro con 1 diente ausente ( $5 \%$ ). En la mandíbula se encontró un máximo de 18 dientes ausentes ( $83 \%$ ) en 1 perro, y como mínimo 1 diente ausente $(5 \%)$ en 1 perro.

De los 50 perros de la muestra, 31 de ellos fueron hembras y 19 fueron machos. En el caso de las hembras, se encontró un caso con 30 dientes ausentes, y 2 perros con solo 4 dientes faltantes; dos perros mostraron la ausencia de 14 dientes $(70 \%)$, y solo 1 perro con 1 diente ausente ( 5 $\%)$. En el grupo de machos se encontraron dos perros con 30 dientes ausentes, y solo un perro con 5 dientes ausentes; en el caso del maxilar se encontraron 14 dientes ausentes $(70 \%)$ como máximo, y como mínimo, 2 dientes ausentes $(10 \%)$ en 1 perro.

En las hembras se encontró 1 perro con 16 dientes ausentes (73\%), y 1 perro con 1 diente ausente ( $5 \%$ ) en la mandíbula, que constituyen las cantidades máxima y mínima respectivamente de dientes ausentes. Del mismo modo, entre los machos se encontró un perro con 18 dientes ausentes $(82 \%)$ y 1 perro con solo 3 dientes ausentes $(14 \%)$ en la mandíbula.

De los 40 perros de talla mediana, 3 mostraron mayor ausencia de dientes (30 dientes), y 2 perros mostraron la menor ausencia ( 4 dientes). En esta misma talla, se evidenció la falta, como máximo, de 14 dientes (70 \%) en el maxilar, así como de 1 diente ausente (5\%) como mínimo. En la mandíbula, por su parte, las cantidades mínima y máxima de dientes faltantes fueron de 18 (82\%) y $1(5 \%)$ respectivamente.

Según la clasificación por dientes, el diente de mayor ausencia en el maxilar es el tercer premolar derecho, ausente en 38 animales, que representan el $76 \%$.

En la mandíbula, se notó que el tercer premolar izquierdo fue el de mayor ausencia, faltando este en 42 perros, que constituye el $84 \%$ de los casos.

Como contraparte, el diente menos comprometido en el maxilar fufe el cuarto premolar izquierdo, que estuvo ausente en solo 3 perros, que constituye el $6 \%$ de la muestra.

En la mandíbula, tanto el primer molar derecho como el izquierdo estuvieron siempre presentes, representando esto el $0 \%$ de ausencia.

En los machos, el diente más comprometido fue el tercer premolar izquierdo del maxilar, estando ausente en el $95 \%$ de los casos. Del mismo modo, en el grupo de hembras, los dientes más comprometidos fueron el segundo y tercer premolares del lado derecho de la mandíbula, con una ausencia de ambos en el $84 \%$ de los casos.

En la talla mediana, la pieza dentaria más comprometida fue el tercer premolar del maxilar izquierdo, mostrando una ausencia en el $85 \%$ de casos.

De los 50 perros, se encontró que 15 de ellos presentaban persistencia de caninos de leche, cuya cantidad estuvo entre 1 y 4 dientes persistentes. El $87 \%$ de estos 15 casos mostraban talla mediana, y el $13 \%$ restante era de talla grande. El $27 \%$ de los casos se verificó en machos, y el 73 $\%$, en hembras. La edad varió en un rango de 1 a 
4 años de edad. El arco dentario maxilar es el más comprometido en este caso.

En lo que respecta a la edad, se tuvieron perros en un rango de 1 a 11 años, y los datos hallados no variaron con la edad, es decir, no se observa correlación con esta variable.

El único caso de simetría bilateral encontrada en los arcos dentarios es la presencia constante del primer molar de la mandíbula, el cual estuvo presente en todos los casos. Los demás dientes siempre estuvieron ausentes en uno $\mathrm{u}$ otro caso.

\section{CONCLUSIONES}

1. Todos los perros sin pelo del Perú estudiados mostraron ausencia de dientes. El máximo de piezas dentales ausentes fue de 30, y el mínimo, de 4.

2. La ausencia promedio fue de 18 dientes.

3. No existe bilateralidad respecto a la ausencia de dientes.

4. El diente con mayor frecuencia de ausencia es el tercer premolar izquierdo del arco mandibular, ausente en 42 perros, es decir, en $84 \%$ de la muestra.

5. El primer molar del lado derecho y del lado izquierdo de la mandíbula siempre está presente.

6. El promedio de ausencia en ambos arcos dentarios es de 9 dientes.

7. En promedio, los machos carecieron de 20 piezas dentales, y las hembras, de 17 dientes.

8. La persistencia de caninos de leche es más evidente en el maxilar.
9. La ausencia de dientes no es dependiente de la talla (mediana, grande y chica), y tampoco depende del sexo.

10. La edad no influye significativamente en la ausencia de dientes.

\section{RECOMENDACIONES}

1. El uso de pruebas auxiliares, como las radiográficas u otras, para tener una mejor idea de la causa de la ausencia de dientes en esta raza.

2. Realizar estudios genealógicos para poder determinar la heredabilidad de esta característica y mejorar la dentición de la raza.

\section{REFERENCIAS BIBLIOGRÁFICAS}

1. El Peruano. Normas legales. Año XIX, No 7793, p. 211663. Ley 27537.

2. I. N. C. Departamental de Cultura. http:// incdepiura.perucultural.org.pe/zona 4 b.htm (2001-10-7).

3. Congreso de la República. Proyectos de Ley. bttp://200.37.159.7/paracas/pr.../bb73299 00bf5046705256b1f74b?

4. León A. 1994. El perro sin pelo del Perú. Perú, Kennel Club Peruano.

5. Weiss P. 1976. El perroperuano sin pelo. Museo Nacional de Arqueología y Antropología. Serie paleobiológica, Lima, Perú.

6. Federación Cinológica Internacional. Estándar F. C. I. No 310. 25/04/2001

7. Dellman D. H., Brown E. M. 1980. Histología Veterinaria. Editorial Acribia, Zaragoza, España, 231-236: 489-493 pp.

8. Hoskins J. D. 1993. Pediatría Veterinaria. Perros y gatos. Nueva Editorial Interamericana, México D. F., México, 156-158 pp. 
9. Eisenmenger E., Zetner K. 1985. Odontología Veterinaria. Ediciones Marzo 80, Barcelona, España, 17-19: 61-62: 235-236 pp.

10. Sisson S., Grossman J. D. 1994. Anatomía de los animales domésticos. Tomo II. Salvat, México D. F., México, 1690-1692 pp.
11. Abramovich A. 1999. Histologia y embriología dentaria. Editorial Médica Panamericana, Buenos Aires, Argentina, 293-301 pp.

12. Holmstrom S. E., Frost P., Eisner E. R. 2000. Técnicas dentales en perros y gatos. McGrawHill Interamericana, México D. F., México, 13-27 pp. 